\title{
Rifamycins, Alone and in Combination
}

\author{
David M. Rothstein \\ David Rothstein Consulting LLC, Lexington, Massachusetts 02421 \\ Correspondence: dmrothstein@gmail.com
}

\begin{abstract}
Rifamycins inhibit RNA polymerase of most bacterial genera. Rifampicin remains part of combination therapy for treating tuberculosis (TB), and for treating Gram-positive prosthetic joint and valve infections, in which biofilms are prominent. Rifabutin has use for AIDS patients in treating mycobacterial infections TB and Mycobacterium avium complex (MAC), having fewer drug-drug interactions that interfere with AIDS medications. Rifabutin is occasionally used in combination to eradicate Helicobacter pylori (peptic ulcer disease). Rifapentine has yet to fulfill its potential in reducing time of treatment for TB. Rifaximin is a monotherapeutic agent to treat gastrointestinal $(\mathrm{Gl})$ disorders, such as hepatic encephalopathy, irritable bowel syndrome, and travelers' diarrhea. Rifaximin is confined to the Gl tract because it is not systemically absorbed on oral dosing, achieving high local concentrations, and showing anti-inflammatory properties in addition to its antibacterial activity. Resistance issues are unavoidable with all the rifamycins when the bioburden is high, because of mutations that modify RNA polymerase.
\end{abstract}

$T^{\mathrm{h}}$ he four rifamycins approved for clinical use, rifampicin, rifabutin, rifapentine, and rifaximin (Fig. 1), are available as orally formulated agents derived from rifamycin SV, the natural product of Amycolatopsis mediterranei (alias Streptomyces mediterranei) (Tupin et al. 2010). The rifamycins are transcriptional inhibitors, and bind specifically to the $\beta$ subunit of RNA polymerases from a broad range of bacteria while showing little or no activity against human RNA polymerases (Chen and Kaye 2009; Forrest and Tamura 2010).

Because rifamycins bind and inhibit most bacterial RNA polymerases, their spectra of activity are largely dictated by entry or exclusion from the bacterial cytoplasm. Rifampicin has potent activity against a variety of pathogens, including mycobacteria, Gram-positive cocci (notably staphylococci and streptococci), Clostridium difficile, and has activity against select Gram-negative pathogens Neiserria meningitides, N. gonorrhoeae, and Hemophilus influenza. The majority of Gram-negative pathogens are not susceptible to rifampicin (Chen and Kaye 2009; Forrest and Tamura 2010). The other rifamycins have similar spectra and potency (Table 1), although they differ substantially in pharmacokinetic properties (Table 2).

Rifamycins induce expression of human P450 cytochrome oxidases, notably CYP3A4, as well as the human $\mathrm{P}$ glycoprotein $\mathrm{ABC}$ transporter, which can cause drug-drug interactions that are a major complication in therapy (Burman et al. 2001). In a fortunate irony, the inducing properties of rifaximin, a drug well designed to treat gastrointestinal (GI) disorders, is

Editors: Lynn L. Silver and Karen Bush

Additional Perspectives on Antibiotics and Antibiotic Resistance available at www.perspectivesinmedicine.org

Copyright (C) 2016 Cold Spring Harbor Laboratory Press; all rights reserved

Advanced Online Article. Cite this article as Cold Spring Harb Perspect Med doi: 10.1101/cshperspect.a027011 
D.M. Rothstein

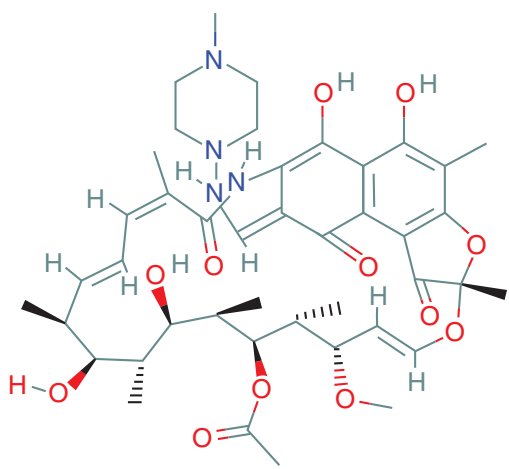

Rifampicin

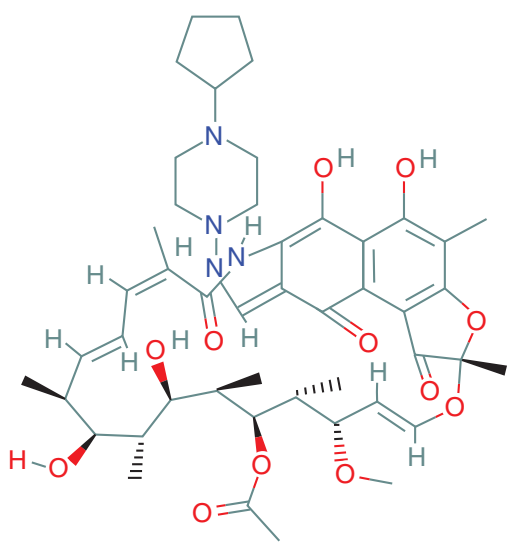

Rifapentine

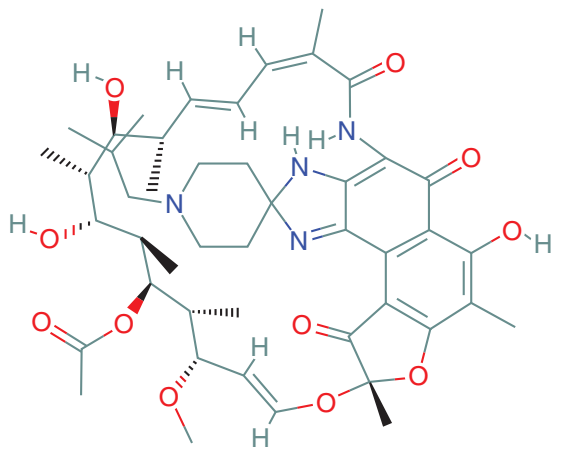

Rifabutin

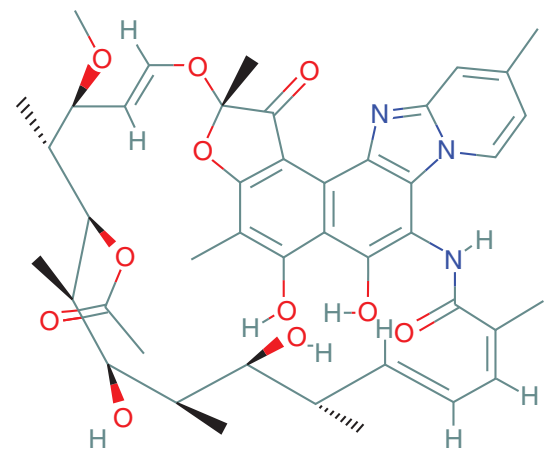

Rifaximin

Figure 1. Chemical structures of approved rifamycins. Clockwise (from top left): rifampicin, rifabutin, rifaximin, and rifapentine.

probably an asset to therapy (see "rifaximin" section below.)

\section{RIFAMYCIN-RESISTANCE POTENTIAL AND ITS INFLUENCE ON RIFAMYCIN DRUG ADMINISTRATION}

The high frequency of rifamycin-resistance development among all susceptible bacteria is a pervasive concern. In particular, rifamycins are prone to "endogenous resistance development" (Silver 2011), resulting from mutations in $r p o B$ encoding the $\beta$ subunit of RNA polymerase, the target of rifamycin binding of all susceptible species. Mutations arise during DNA replication, unavoidable mistakes that encode RNA polymerase, which bind rifamycins less tightly. When the bioburden of susceptible bacteria exceeds $10^{8}$, then mutant variants inevitably contain RNA polymerase that fails to bind rifamycins effectively.

Mutations conferring strong rifampicin resistance are cross-resistant to other approved rifamycins (Williams et al. 1998; Wichelhaus et al. 1999; Tupin et al. 2010; Goldstein 2014). No matter how susceptible the original bacteria are, the mutants will take over a population exposed to rifamycins, unless another antibacterial agent is also present to nullify their selective advantage. Hence, whenever the bioburden is assumed to be greater than $10^{8}$, and the goal of therapy is elimination of a pathogen, rifamycins are routinely administered in combination. Monotherapy with approved rifamycins is a 
Rifamycins, Alone and in Combination
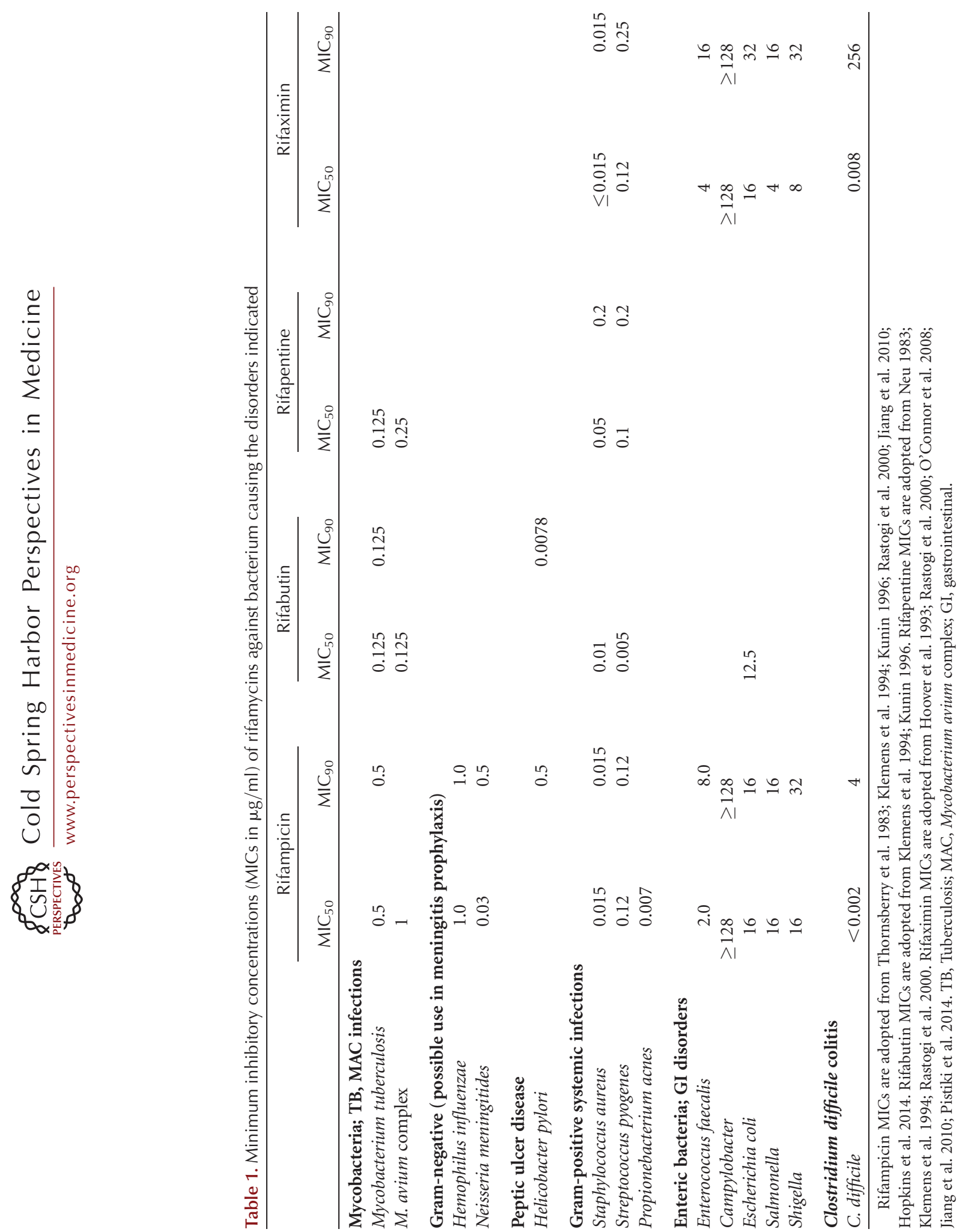
D.M. Rothstein
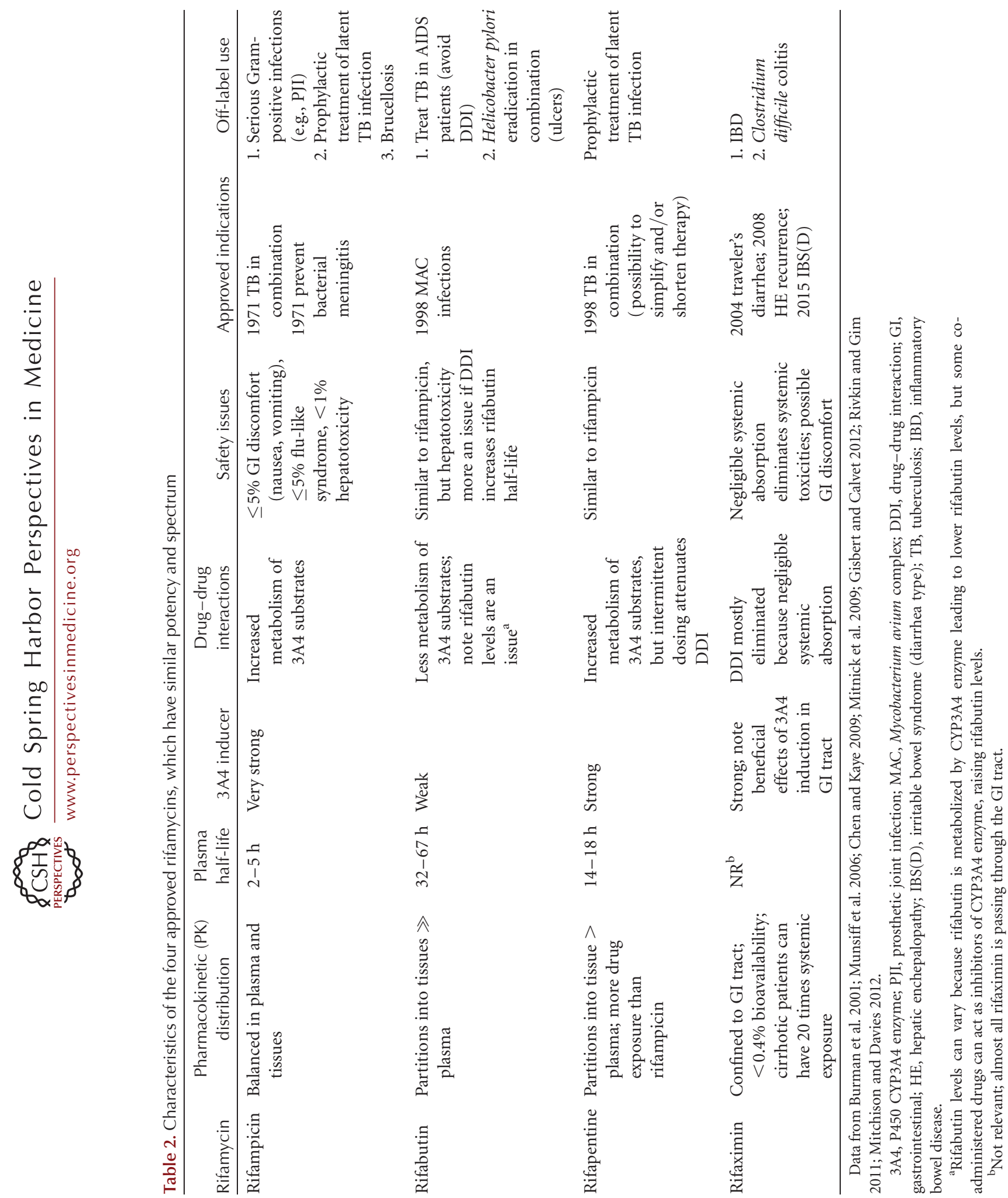
consideration when the bioburden is assumed to be low, for example, as prophylactic therapy.

DNA sequence analysis of resistant isolates selected in vitro indicates that resistance was mediated by a single modification in one of 12 codons of the $r p o B$ gene of Staphylococcus aureus, resulting in a single change in one of at least 25 nucleotide sites (Wichelhaus et al. 1999; Murphy et al. 2006; Goldstein 2014). Analysis of rifamycin-resistant clinical isolates of $S$. aureus revealed that resistant strains predominantly contained mutations in one or more of the 12 codons in the $r p o B$ gene shown to mediate rifamycin resistance in vitro. Among the resistant clinical isolates, single mutational events in the $r p o B$ gene have been detected within seven of these critical codons found by in vitro selection. When clinical isolates containing multiple mutations in the $r p o B$ gene are included in the analysis, modifications in all but one of the 12 critical codons defined by in vitro selection experiments have been identified among clinical isolates (Aubry-Damon et al. 1998; Wichelhaus et al. 1999; O’Neill et al. 2006). One potential mutagenic hotspot was detected among clinical isolates at codon 481 mediating a histidine to asparagine change (Wichelhaus et al. 2002; O'Neill et al. 2006). Thus, in S. aureus, resistance is mediated in the laboratory and in the clinic primarily by mutations within the $r p o B$ gene, mostly residing in cluster I of the rifampin-resistancedetermining region (Wichelhaus et al. 2002).

Competitive fitness assays, in which a rifamycin-resistant strain and its isogenic rifamycin-sensitive parent are cogrown in the absence of rifampicin for multiple generations, reveal that the proportion of the resistant strain diminishes, indicating a fitness cost of these $r p o B$ mutations (Wichelhaus et al. 2002; O'Neill et al. 2006). Strains carrying a mutation in codon 481 of the $S$. aureus $r p o B$ gene may not show this fitness deficit (Wichelhaus et al. 2002), which may explain its prevalence among clinical isolates. However, others have observed diminished fitness of strains carrying this allele as well as other $r p o B$ mutations (O’Neill et al. 2006).

These competitive fitness experiments predict that rifamycin-resistant strains would not compete well in the longer run, in an environ- ment lacking rifamycins. However, laboratory experiments might exaggerate the long-term fitness deficits of rifamycin-resistant strains, because of the possible acquisition of compensatory mutations that would reduce the handicap of rifamycin-resistant alleles (O’Neill et al. 2006).

Rifamycin resistance in Mycobacterium tuberculosis, the pathogen responsible for $\mathrm{TB}$, is also predominantly mediated by mutations in its $r p o B$ gene. Rifamycin resistance selected in vitro results in modifications in homologous regions of the rifampin-resistance-determining region compared with $S$. aureus or Escherichia coli (Murphy et al. 2006; Goldstein 2014). Clinical isolates of resistant strains of $M$. tuberculosis similarly contain mutations in the key codons encoding the capacity to bind rifamycins (Goldstein 2014). Rifamycin-resistant strains of $M$. tuberculosis were also associated with a competitive fitness disadvantage (Billington et al. 1999; Mariam et al. 2004).

The most important consideration of endogenous resistance potential, in all therapeutic areas, can be summarized as follows. If the infecting population of rifamycin-susceptible bacteria exceeds $10^{8}$, then there are a handful of rifamycin-resistant mutants in the infecting population. In this situation, selection clearly favors the resistant mutant(s), resulting in their rapid overgrowth despite any minor growth deficits of the rifamycin-resistant strains.

\section{TUBERCULOSIS (TB)}

Rifampicin was approved by the Food and Drug Administration (FDA) in 1971 for the treatment of TB. Combination therapy had already been established as the standard of care, with the discovery that streptomycin monotherapy, first tested in 1946, resulted in short-lived improvements, with the frequent emergence of streptomycin-resistant bacteria (Fox et al. 1999; Nuermberger et al. 2010; Field et al. 2012). Combination therapy of streptomycin together with para-aminosalicylic acid and, subsequently, with isoniazid in the early 1950s, made for a considerably more robust therapy, although 18 to 24 mo of treatment were required 
D.M. Rothstein

(Fox et al. 1999; Mitchison and Davies 2012). The inclusion of rifampicin resulted in fewer relapses, and it was found that therapy could be shortened to $9 \mathrm{mo}$, and with subsequent improvements to the current 6-mo regimen.

Rifampicin was found to have unique bactericidal activity against persistent $M$. tuberculosis using in vitro and cell culture systems (Fox et al. 1999). Human studies of multiple combinations of drugs confirmed the importance of rifampicin (Jindani et al. 2003). Isoniazid was particularly active in the first week against metabolically active bacteria, whereas rifampicin contributed to bactericidal activity during the first week. Rifampicin continued to act in the coming months against the persistent, metabolically quiescent population of bacteria, often residing inside of host cells. More recently, pyrazinamide was found to contribute bactericidal activity against the persistent population (Mitchison and Davies 2012). These studies led to the combination therapy that is used to treat susceptible $M$ tuberculosis infections, that is, 2 mo of isoniazid, rifampicin, pyrazinamide, and ethambutol, followed by 4 mo of continuation therapy consisting of daily dosing with isoniazid and rifampicin (Jindani et al. 2014).

Nausea is one common side effect of combination therapy, although generally it is not sufficient to stop therapy. Drug-induced hepatitis is rare, occurring in $2.5 \%$ of patients, and is generally attributed to the isoniazid and/or pyrazinamide components. Flu-like syndrome is experienced by a small minority of patients exposed to rifampicin and, rarely among this minority, can include thrombocytopenia, hemolytic anemia, and acute renal failure, resulting in discontinuation of therapy. The occurrence of these events is not dose related and may involve immune response to the drug (Burman et al. 2001; Mitnick et al. 2009).

With such a complex regimen and its side effects, adherence becomes an important issue and the main reason for treatment failure. Shortening therapy would be a major advance. One strategy is to raise the dose of rifampicin, which at $600 \mathrm{mg} / \mathrm{d}$ in the standard formulation, is at the low end of the curve to achieve optimal efficacy (Mitnick et al. 2009; Mitchison and Da- vies 2012), with the additional knowledge that higher doses generally are tolerable (Boeree et al. 2015). Another possibility for shortening therapy is the incorporation of other drugs.

Rifapentine, approved by the FDA in 1998 for TB therapy, is a slightly more potent rifamycin derivative than is rifampicin, and has a five-fold increased exposure as a result of a longer half-life (Burman et al. 2001; Mitnick et al. 2009; Nuermberger et al. 2010). Preclinical studies suggested that if rifapentine replaced rifampicin, TB therapy might be shortened (Mitchison and Davies 2012). The results of a recent phase 3 clinical trial showed that the last 4 mo of the 6-mo therapy could be simplified with weekly dosing of rifapentine and moxifloxacin (a quinolone), but not shortened (Jindani et al. 2014).

Rifabutin is a potent antimycobacterial agent that partitions mostly into tissues as opposed to plasma (Burman et al. 2001; Mitnick et al. 2009). Rifabutin was approved in 1994 for the treatment of infections caused by Mycobacterium avium complex (MAC) (O'Brien and Vernon 1998; Mitnick et al. 2009). Rifabutin is a weaker inducer of CYP3A4, thereby diminishing drug-drug interactions, and is therefore often chosen for tuberculosis therapy for AIDS patients. In essence, patients are administered a watered-down version of TB chemotherapy in an attempt to minimize difficult drugdrug interactions; rifabutin can increase the elimination of essential antiretroviral medications, while the retroviral medications can increase the half-life of rifabutin, which can result in hepatotoxicity (Burman et al. 2006; Zhang et al. 2011; Regazzi et al. 2014).

Adherence issues leading to interrupted TB therapy can result in incomplete killing of persistent bacteria, requiring prolonged therapy. Interrupted therapy can also result in the selection of resistant $M$. tuberculosis mutants, for example, rifamycin-resistant mutants. Selection of resistant mutants leads to treatment failure, requiring a change from first-line agents to second-line agents.

Undertreatment can also select for mutants. For example, when AIDS patients were treated with intermittent rifabutin-based ther- 
apy, the exposure to rifamycin was diminished to avoid drug-drug interactions with AIDS medications. The majority of these AIDS patients were cured. For those patients who experienced relapses, however, usually a rifamycinresistant mutant strain had been selected during therapy (Burman et al. 2006). There are alternative antibacterials to treat drug-resistant $\mathrm{TB}$ (Mitnick et al. 2009; Nuermberger et al. 2010; Field et al. 2012), but to lose the use of rifamycins, the most powerful killing agent, is a serious setback for an AIDS patient.

\section{THE USE OF RIFAMPICIN AS A SINGLE AGENT FOR PROPHYLACTIC TREATMENT OF LATENT TB}

A positive skin test for $\mathrm{TB}$ in the absence of clinical symptoms may indicate latent TB, a symptom-free quiescent infection. In the United States, most cases of TB are the result of reactivated infection (Horsburgh and Rubin 2011). The expectation is that $5 \%$ to $15 \%$ of latent carriers in the United States are expected to develop an active infection during their lifetimes (Getahun et al. 2015), an estimate that may be a moving target depending on immigration, the proportion of immune-compromised individuals, etc. Therefore, prophylactic treatment to prevent active outbreak is a consideration.

Because the bioburden is low, latent TB is often treated by shortened therapies of 3 to 4 mo. In fact, a variety of treatment options is used, including rifampicin and isoniazid for 3 mo or for 4 mo, rifapentine and isoniazid weekly for $3 \mathrm{mo}$, isoniazid alone for $3,4,6$, or $9 \mathrm{mo}$, and rifampicin monotherapy for 3 or for 4 mo (Stagg et al. 2014; Getahun et al. 2015). Although these treatments are probably effective (i.e., result in a reduced conversion to active $\mathrm{TB}$ compared with untreated patients), it has been challenging to standardize treatment. It is probably difficult to determine the medical superiority of a particular treatment to prevent an outbreak of active TB, an infrequent event, as the end point of clinical trials. As mentioned previously, rifampicin is a well-tolerated drug, so there is a temptation to use rifampicin monotherapy, diminishing adherence issues and costs. A word of caution, however, is that the failure of latent TB treatment may be rare and may not appear immediately, but the negative consequence of failure could be severe, such as a lifetime of battling an M. tuberculosis strain that has been selected for resistance to rifamycins. Although the bioburden for any one patient harboring a latent TB infection is low, the communal bioburden of a group of such patients can be predicted to include a rifampicin-resistant mutant, which could be selected in the unlucky individual undergoing rifampicin as a stand-alone therapy. If the severity of selecting a resistant pathogen (and not simply a failed therapy) has not been properly taken into account, the rifampicin stand-alone strategy perhaps should be abandoned.

The 3-mo isoniazid-rifampicin daily therapy is a more intuitively appealing choice to treat latent $\mathrm{TB}$, because isoniazid would protect against development of a rifampicin-resistant active infection. However, this strategy will not be secure if the frequency of isoniazid resistance rises, as currently the susceptibility of the latently infecting bacteria is not determined before treatment.

\section{RIFAMYCINS IN COMBINATION THERAPY BEYOND THE REALM OF MYCOBACTERIA; TREATING PEPTIC ULCER DISEASE}

It is generally accepted that combination antibiotic therapy is necessary to eradicate Helicobacter pylori from stomach tissue, to cure peptic ulcer disease. Rifabutin, with its tissue penetrating ability, has been shown to be effective in combination with amoxicillin and other antibiotics in a series of small clinical trials (Gisbert and Calvet 2012). A practical strategy is to use rifabutin in combination as a backup if first-line therapy fails, knowing that rifamycin resistance is currently infrequently encountered in $H$. $p y$ lori strains. Amoxicillin resistance is also very rare. Gisbert and Calvet envision the role of rifabutin to be one reserved for the more recalcitrant cases of peptic ulcer disease, not to be overused, to prevent selection of rifampicinresistant $M$. tuberculosis in the populace, for example, among latent carriers of TB, during the $10-12 \mathrm{~d}$ required for therapy. 
D.M. Rothstein

\section{RIFAMPICIN AND SYSTEMIC GRAM-POSITIVE INFECTIONS}

The possibility of using rifampicin in combination therapy against Gram-positive infections was recognized early after its approval for treating TB. Rifamycins have potent activity against both staphylococci and streptococci, the predominant pathogens causing systemic infections, such as bacteremia, abscesses, endocarditis, and foreign body infections. If a partnering drug could prevent the emergence of rifampicin-resistant mutants, then the combination could provide great benefit (Sanders 1976). It is very important that the pharmacokinetic properties of the partnering drug are suitable, that is, that the second drug is always sufficiently present to prevent outgrowth of the tiny minority of rifampicin-resistant organisms, while allowing rifampicin, with its favorable potency and tissue penetration, to exert its activity (Achermann et al. 2013).

In vitro evaluation of rifampicin combinations did not provide clear-cut guidance in choosing a second drug. Isobolograms or time-kill curves often showed apparent synergy at sub-minimum inhibitory concentration (MIC) levels of two drugs, while showing interference or antagonism at higher concentrations, particularly when rifampicin was tested in combination with bactericidal drugs (Perlroth et al. 2008; Forrest and Tamura 2010). In general, these studies minimized the apparent benefit of pairing rifampicin with bactericidal agents, while exaggerating benefits of bacteriostatic agents, such as minocycline (Forrest and $\mathrm{Ta}$ mura 2010).

Animal models did not provide compelling support for rifampicin adjunct therapy, except for foreign-body models described in the next section. Native valve endocarditis models and bacteremia models (mouse, rat, and rabbit) have provided inconsistent support for rifampicin adjunct therapy with linezolid, daptomycin, or fusidic acid. However, there was no evidence for greater efficacy of rifampicin as an adjunct with vancomycin, the mainstay drug for serious Gram-positive infections (Perlroth et al. 2008; Forrest and Tamura 2010).
Clinical publications have included case studies of one or a handful of patients undergoing combination therapy, including rifampicin, to treat native valve endocarditis and/or bacteremia, with mixed results (Forrest and Tamura 2010). In addition, several small prospective clinical combination trials were performed (Van der Auwera et al. 1985; Dworkin et al. 1989; Levine et al. 1991; Heldman et al. 1996; Schrenzel et al. 2004). The difficulty with all of these trials is they were underpowered to be convincing, given that the baseline benefit of monotherapy was substantial. How could a trial convincingly show benefit when each arm of the study contained fewer than 20 subjects, and when monotherapy was effective in most patients? However, one clinical trial showed approximate equivalence in medical outcome and a qualitative advantage of orally administered combination therapy (rifampicin with fleroxacin, a quinolone) to treat bacteremia, compared with IV-administered vancomycin, reducing hospitalizations by $11 \mathrm{~d}$ per patient (Schrenzel et al. 2004). The American Heart Association has not endorsed rifampicin combination therapy for treating native valve endocarditis or bacteremia. Perhaps a well-powered clinical study, with a carefully designed and optimized protocol, would clarify this issue.

\section{RIFAMPICIN IN COMBINATION THERAPY TO TREAT PROSTHETIC JOINT INFECTIONS}

Rifampicin combination therapy has more obvious advantages in treating prosthetic joint infections (PJIs), mostly resulting from staphylococcal infections following hip or knee replacements (Zimmerli et al. 2004). The foreign body provides a surface devoid of host innate defenses, and an opportunity for biofilms to develop. The bacteria secrete exopolysaccharides that can adhere to the device surface, and provide a barrier, protecting bacteria from phagocytes, antibodies, and antibiotics (Costerton et al. 1999; Jacqueline and Caillon 2014). MICs for most drugs are 100-1000 times higher in biofilms (Jacqueline and Caillon 2014). However, rifampicin retains more activity 
against biofilms of staphylococci than other antibiotics (Widmer et al. 1990; Amorena et al. 1999; Saginur et al. 2006; Perlroth et al. 2008; Gomes et al. 2012; Jacqueline and Caillon 2014). Rifampicin, in addition, shows activity against biofilms of Propionibacterium acnes, another prominent PJI pathogen (Furustrand Tafin et al. 2012).

Animal models of foreign body infections reinforce the idea that rifampicin has a unique antibacterial role in PJI. In the guinea pig cage model, staphylococci are injected into cages that have been surgically implanted subcutaneously in guinea pigs (Zimmerli et al. 1982). This model system can test for efficacy of antibiotics against both the planktonic cells, and biofilms on cage surfaces. The combinations of rifampicin with linezolid (Baldoni et al. 2009), with daptomycin (John et al. 2009), and with fosfomycin (Mihailescu et al. 2014), showed improved results compared with monotherapy, and potential for clinical efficacy. An experimental rabbit model of PJI also showed that rifampicin and daptomycin were an effective pair against methicillin-resistant $S$. aureus (MRSA) infection of a joint implant compared with daptomycin monotherapy, resulting in the suppression of resistance to daptomycin and to rifampicin. Similar results were observed for vancomycin paired with rifampicin (SalehMghir et al. 2011). An experimental rat model, using a titanium wire implanted into the tibia to simulate a foreign body implant, suggested that rifampicin combinations with both linezolid and vancomycin reduced MRSA more effectively than monotherapy with linezolid or vancomycin (Vergidis et al. 2011). It is encouraging and consistent that rifampicin combinations shown efficacy in these three distinct animal models of PJI.

Approximately $1 \%$ of patients having a prosthetic implant experience PJI. Clinical evidence showed that some PJI infections could be successfully treated by using combination antibiotic therapy with rifampicin playing a central role. For the 11 patients in the first study, removal of the implant to treat the infection (the standard of care) was not practical (Widmer et al. 1992). Before antibiotic administration, patients had a surgical procedure to physically clean the area surrounding the implant, removing hopelessly infected and inflamed tissue (debridement) while leaving the prosthesis in place. Treatment of PJIs with a rifampicin/ciprofloxacin combination was successful in nine of 11 patients who showed no symptoms of infection after 2 yr of follow-up. These results were sufficiently encouraging to launch a prospective, blinded randomized trial in which patients were enrolled with early PJI infections, mostly of $S$. aureus, to determine whether adjunct therapy with rifampicin was beneficial (Zimmerli et al. 1998). All patients were treated initially with an IV course of the $\beta$-lactam flucloxacillin or vancomycin for $2 \mathrm{wk}$. The test group was also treated with rifampicin during the initial 2-wk treatment. For the long-term continuation phase, the control group was administered oral ciprofloxacin monotherapy, while the test group was administered both oral ciprofloxacin and rifampicin. All 12 patients able to complete the test regimen were cured of the infection, whereas only seven of 12 patients administered ciprofloxacin monotherapy were cured. More recently, a clinical study of 43 patients infected primarily with MRSA reinforced the concept that prosthetic retention also applies to MRSA infections (Peel et al. 2013).

The clinical evidence supporting PJI regimens includes numerous additional case studies, but still does not carry the statistical power of pivotal clinical trials for obtaining drug approval. In the absence of this well-documented approval process, with a defined FDA label prescribing drug administration, the medical profession has resorted to guidances representing the current thinking of experts in the field. In the Infectious Disease Society of America (IDSA) guidance (Osmon et al. 2013), there was consensus in the definition of PJI, methods of detection of infections, the use of antibacterial therapy, and when to attempt to salvage a prosthesis without surgical removal. There was recognition of alternative preferences for particular procedures and antibiotic strategies. However, on the idea of the centrality of rifampicin in treating these biofilm-prone infections, the committee reached consensus. 
D.M. Rothstein

Prosthetic valve endocarditis, similar to PJI, involves infection of a prosthetic surface prone to biofilm infections. The latest guidelines from The European Society of Cardiology (ESC) has endorsed rifampicin combination therapy to treat endocarditis associated with prosthetic valves, but not native valve endocarditis (Habib et al. 2015).

\section{RIFAXIMIN TREATMENT OF GI DISORDERS; GENERAL PROPERTIES OF RIFAXIMIN}

Rifaximin is an oral drug confined to the GI tract. Its oral bioavailability is $<0.4 \%$ (Darkoh et al. 2010). Stool samples contained $8000 \mu \mathrm{g} /$ $\mathrm{ml}$ of rifaximin after $3 \mathrm{~d}$ of treatment at $800 \mathrm{mg} / \mathrm{d}$ (Jiang et al. 2000). It has been shown that bile salts increase rifaximin solubility, suggesting that there may be a gradient of rifaximin activity that diminishes as the drug proceeds through the GI tract as bile salts diminish in concentration (Darkoh et al. 2010).

The activity spectrum of rifaximin in standard MIC testing is similar to that of rifampicin: very potent activity against Gram-positive staphylococci and streptococci, C. difficile, and Neisseria, and modest activity against $H$. influenza (Table 1). Rifaximin has high MICs against most Gram-negative bacteria, such as Enterobacteriaceae, and these strains would normally be considered resistant, for example, MICs in the range of $16 \mu \mathrm{g} / \mathrm{ml}, 32 \mu \mathrm{g} / \mathrm{ml}$, or higher (Rivkin and Gim 2011). However, rifaximin is a broad-spectrum agent in the GI tract, because its very high nominal concentration greatly exceeds the MICs of Gram-negative bacteria.

Rifaximin has few downside effects, given its GI localization. In clinical trials, it has been difficult to distinguish adverse events observed in the rifaximin test group and the placebo group even after 6 mo of dosing, and rifaximin is devoid of drug-drug interactions characteristic of rifampicin (Rivkin and Gim 2011). The use of rifaxamin has been explored in several GI indications, with growing formal FDA approvals: traveler's diarrhea (TD) in 2004, reduction in recurrence of hepatic encephalopathy (HE) in 2010, and irritable bowel syndrome (IBS) in May 2015.

\section{RIFAXIMIN AS AN EFFECTOR OF THE PREGNANE RECEPTOR IN THE GI TRACT}

Rifaximin, like rifampicin, is classified as a strong inducer of the CYP3A4 enzyme in hepatocyte cell culture testing. This induction is mediated by the binding of either rifamycin to the pregnane $\mathrm{X}$ receptor, a master regulator of genes involved in xenobiotic detoxification, bile biosynthesis, and other functions (Hirota 2015). However, because rifaximin is confined to the GI tract in vivo, there is no significant induction of CYP3A4 in the liver in humans, and consequently, rifaximin causes no drug-drug interactions characteristic of rifampicin (Rivkin and Gim 2011). However, when rifaximin binds to the pregnane receptor in the GI tract, it inhibits NF- $\kappa \mathrm{B}$, a transcription factor, preventing it from activating proinflammatory genes of its pathway (Hirota 2015).

An elegant set of preclinical studies using the mouse model of inflammatory bowel disease (IBD) suggests the importance of rifaximin as an effector of the pregnane receptor. Mice that were subjected to chemical insult were protected from the worst signs of colon damage by rifaximin administration. However, this protection only occurred in the isogenic strain of mouse humanized for the pregnane receptor gene; the rodent pregnane receptor fails to respond to rifamycins (Ma et al. 2007; Cheng et al. 2010). The most likely explanation for the different response of the isogenic mouse containing the humanized pregnane receptor is that rifaximin, acting as agonist of the pregnane receptor, was responsible for the protection from colon damage.

Additional support for the involvement of the pregnane receptor in IBD comes from human studies. The expression of pregnane receptor target genes was significantly reduced in patients having IBD (Langmann et al. 2004).

\section{RIFAXIMIN AND THE TREATMENT OF IBD}

IBD is actually composed of two multifactorial diseases having some common symptoms and genetic predispositions (Cho and Brant 2011). Ulcerative colitis (UC) causes inflammation 
and ulcers specifically in the lining of the colon, and Crohn's disease (CD) can afflict the colon or other regions of the GI tract, and all of its layers. Antibacterial treatments are a consideration because aspects of the inflammatory response may be directed by interactions with the microbiome. The pregnane receptor gene has specific polymorphisms that raise the risk of contracting UC, CD, or both (Dring et al. 2006). This specificity of genetic predisposition suggests that interaction of rifaximin with the pregnane receptor could have a non-antibacterial benefit (described in the previous section), in addition to its antibacterial activity in treating both diseases.

Eighty-three patients were enrolled in a double-blind randomized trial to determine whether rifaximin ameliorated CD symptoms. Progress was monitored with the CD activity index (CDAI) self-assessment. The group that received rifaximin for 12 wk experienced a 52\% remission rate, whereas placebo remission rate was $33 \%$. The difference was not statistically significant, although the subset of patients who entered the study with a high C-reactive protein (CRP) score (a biomarker for inflammation) did show a significant difference (Prantera et al. 2006).

In a second double-blind randomized trial of 402 patients, treated either with rifaximin as described above or placebo, a $62 \%$ remission was observed in the rifaximin group compared with $43 \%$ in the placebo group (Prantera et al. 2012). After an additional $12 \mathrm{wk}$, the remission rate in the rifaximin group was $45 \%$, whereas the remission rate in the placebo group was $29 \%$. The rifaximin treatment showed some lasting benefit compared with placebo. However, the diminished rate of the test group raises the possibility that additional rifaximin treatments might be necessary to sustain benefit. Rifaximin was generally well tolerated in both these studies, with no serious adverse events. Again, the subgroup that had the high CRP level at the initiation of the study (indicating a stronger baseline inflammatory response) experienced a more significant benefit, suggesting that the anti-inflammatory properties of rifaximin could be beneficial to this subgroup.
Several small clinical studies of UC patients refractory to steroid use were tested with rifaximin as an adjunct therapy. All patients were treated with mesalazine, a nonsteroidal anti-inflammatory agent that localizes in the colon. The addition of rifaximin resulted in reduction in stool frequency, diminished rectal bleeding, and in sigmoidoscopic score compared with the placebo group, objective criteria that were encouraging of future testing (Guslandi 2011).

Rifaximin treatment resulted in significant relief of IBD symptoms, however transient these changes might be. Rifaximin treatment was well tolerated with few serious side effects. Positive effects could be a consequence of rifaximin's antibacterial activity, and its anti-inflammatory activity as effector of the pregnane receptor, particularly among patients who may be prone to inflammation (i.e., patients having high CRP levels).

\section{RIFAXIMIN AS A TREATMENT IN IRRITABLE BOWEL SYNDROME (IBS)}

IBS is characterized by irregular bowel patterns, recurrent abdominal pain, bloating, and flatulence, but is devoid of the physical signs of inflammation and ulcers that are characteristic of IBD. Although IBS is not as serious or life threatening as IBD is, IBS afflicts up to $15 \%$ of the U.S. population and is a major source of morbidity (Iorio et al. 2015). Lactulose gas tests indicated that subjects having IBS were more prone to bacterial overgrowth in the small intestine (SIBO) (Saadi and McCallum 2013). Antibacterials are among a variety of medicines prescribed for IBS because of the possibility of correcting this imbalance in IBS patients (Kassinen et al. 2007).

Pivotal double-blind clinical trials led to approval of rifaximin for treating IBS(D) (diarrhea type), which was announced by the FDA in May 2015. A total of 1260 IBS subjects were enrolled in these two parallel randomized double-blind phase 3 studies. Four weeks after treatment in the first study, $40.8 \%$ of subjects administered rifaximin for 2 wk reported adequate relief from IBS symptoms (the primary endpoint) compared with $32.2 \%$ for the place- 
D.M. Rothstein

bo group. In the second study, $40.7 \%$ of the test group reported relief from IBS symptoms compared with $31.7 \%$ in the placebo control. Similar observations were reported for specific symptoms such as bloating. All of these results had statistically significant differences among groups. Ten weeks after treatment, the test groups continued to report a higher level of relief than the placebo groups, although the percentage reporting adequate relief from all groups had diminished (Pimentel et al. 2011a).

An important issue for the often-chronic condition of IBS is the potential for retreatment. In fact, a retrospective study of patients who had received multiple treatments suggested that retreatment with rifaximin provided comparable benefit to some subjects (Pimentel et al. 2011b). It is difficult to rule out possible biases of selfselection in patients who decide to seek retreatment. For example, patients who particularly benefited from the first treatment might preferentially have enrolled in the trial, or alternatively, patients who responded best might not have relapsed, and then they would not have enrolled in the second trial. In any case, rifaximin seems to have provided at least temporary benefit to IBS subjects, with potential benefits of retreatment.

\section{RIFAXIMIN TREATMENT OF HEPATIC ENCEPHALOPATHY (HE)}

$\mathrm{HE}$ affects up to $80 \%$ of patients with cirrhotic liver disease, primarily caused by hepatitis C infection, excessive alcohol uptake, and fatty liver disease. Thirty to $45 \%$ of patients experience overt HE, which often requires hospitalization and is manifested by mental and personality changes, impaired cognition, and decreased hand-eye coordination (Scott 2014). Toxic levels of ammonia are thought to be the direct cause of HE. Although there is not a strict correlation of plasma ammonia levels and cognitive symptoms, successful therapies of nonabsorbable disaccharides and/or nonabsorbable antibiotics, correlated with reduction of ammonia in plasma (Sussman 2015). Lactulose, the approved disaccharide in the United States, passes into the colon where it may shift bac- terial metabolism away from ammonia production. Lactulose fermentation in the colon may also create a more acid environment, resulting in ammonia conversion to less permeable $\mathrm{NH}_{4}{ }^{+}$ions.

Rifaximin was approved in 2010 to prevent recurrence of overt HE. For the pivotal phase 3 trial, 299 patients who had experienced at least two episodes of overt HE in the previous $6 \mathrm{mo}$ were enrolled in the trial, and either treated with rifaximin for up to $6 \mathrm{mo}$, or were assigned to the placebo-controlled arm. Lactulose treatment was not a criterion for enrollment but was continued for $91 \%$ of the patients taking this medication, in both arms of the trial. During these 6 mo of treatment, $22.1 \%$ of the rifaximin group had a breakthrough HE event compared with $45.9 \%$ of the placebo group, a statistically significant difference (Bass et al. 2010). The expectation from this trial is that rifaximin will prevent one patient from experiencing an $\mathrm{HE}$ breakthrough for every four patients treated for a 6-mo period.

The data on safety of the rifaximin and placebo arms were comparable (Bass et al. 2010). Small safety differences would be difficult to discern, because lactulose would be expected to contribute more than rifaximin to adverse events. Two cases, however, were terminated from the study because of $C$. difficile infections, only in the treatment arm. Although the $1 \%$ rate of $C$. difficile infection was not unusual for this population group, the result is one that should engender special attention in future investigations because $C$. difficile-associated colitis is life threatening.

The same investigators then performed an open-label clinical trial, in which all 392 patients were treated with rifaximin for $2 \mathrm{yr}$. Enrollment criteria required that all subjects had experienced an episode of HE within the previous year. The baseline characteristics of the subjects were similar to the previous trial, and the protocol was identical to the previous trial except for the longer treatment time. The subjects of this longer trial had a recurrence rate that was comparable to that of the rifaximin arm of the previous study. The rate of recurrence was considerably lower than the placebo arm of the pre- 
vious study, suggesting that rifaximin treatment showed benefit for this prolonged treatment time (Mullen et al. 2014).

However, once again, $1 \%$ of the subjects ( patients) of this trial contracted $C$. difficile. As in the last trial, this 1\% figure was approximately the rate anticipated for patients in a comparable condition (Scott 2014). Again, the appearance of $C$. difficile infections following rifaximin treatment is something to monitor closely in the future to determine whether there is any contribution of rifaximin in promoting C. difficile-associated colitis.

In comparing antibiotic treatment options for HE patients, rifaximin may be the most beneficial (Patidar and Bajaj 2013). Other antibiotics of low bioavailability, such as neomycin, have higher systemic absorption and more serious safety issues. A reasonable medical approach may be to treat initially with lactulose, and then to treat patients having a breakthrough occurrence of $\mathrm{HE}$ with rifaximin. However, it has been shown that generic rifaximin, which contains the amorphous molecule, is absorbed systemically up to 5 times the level when compared with the brand molecule in the rifaximin- $\alpha$ crystal form (Blandizzi et al. 2014), indicating that branded rifaximin is the better choice.

\section{TRAVELER'S DIARRHEA (TD)}

TD is caused by eating or drinking contaminated food or water, usually while visiting a developing country (see wwwnc.cdc.gov/travel/ page/travelers-diarrhea). The most common agents causing TD are Enterobacteriaceae, such as E. coli (ETEC), which secrete toxins. Although usually a self-limiting disease, especially for the majority of noninvasive Enterobacteriaceae, occasionally TD initiates postinfectious IBS. TD was the first approval by the FDA for rifaximin in 2004 to treat uncomplicated cases of TD-no fever or blood in stools - with a 3-d treatment of rifaximin. The studies that led to approval consisted of three randomized and double-blind trials that enrolled subjects visiting Mexico, Guatemala, Jamaica, and Kenya. These trials showed a sig- nificant reduction in duration of diarrhea compared with placebo, or an equivalent response compared with ciprofloxacin (Adachi and DuPont 2006). A subsequent clinical trial again showed significant benefit of rifaximin to treat patients for $3 \mathrm{~d}$, showing approximate equivalence in time to resolution compared with ciprofloxacin. However, the ciprofloxacin group was significantly superior in having fewer treatment failures, and having a higher rate of microbiological eradication of pathogens $(92.5 \%$ for ciprofloxacin, $76.7 \%$ for rifaximin), and having a more favorable response to invasive pathogens (e.g., Shigella) (Taylor et al. 2006).

More recently a meta-analysis summarized the results of four double-blind trials, conducted to test for prevention of TD. Subjects were dosed with rifaximin prophylactically during a trip. Subjects of the rifaximin test group had a lower rate of contracting TD than did the placebo group. The results taken together showed that for every four subjects who took rifaximin, one case of TD was prevented (Hu et al. 2012).

In summary rifaximin showed clear benefit in both treating and preventing TD, and equivalence or near equivalence to ciprofloxacin in efficacy. An important consideration is the safety and tolerability of treatment, and here rifaximin has the advantage of confinement to the GI tract, devoid of systemic safety concerns and drug-drug interactions, and being a well-tolerated drug. Despite these apparently favorable factors, the CDC states that "fluoroquinolones are the drugs of choice" if TD patients seek chemotherapy, and makes no mention of rifaximin despite its approval for this indication (see wwwnc.cdc.gov/travel/page/trav elers-diarrhea).

\section{RIFAXIMIN IS PRONE TO RESISTANCE DEVELOPMENT, DESPITE THE PREVAILING SENTIMENT TO THE CONTRARY}

Resistance to rifaximin is mediated in three ways. In the most frequently encountered mechanism, mutations arise during DNA replication, unavoidable mistakes that encode RNA polymerase that binds rifamycins less tightly. The mutations mediating strong resistance to one 
D.M. Rothstein

rifamycin are cross-resistant to all approved rifamycins (Tupin et al. 2010; Goldstein 2014). Hence, whenever the bioburden exceeds $10^{8}$ bacteria, a mutant strongly resistant to all approved rifamycins has been created by an error in DNA replication. (For more details, see the above section on rifamycin resistance.) The other two mechanisms are efflux pumps, which expel rifamycins from Gram-negative bacteria, and modifying enzymes, which are rarely encountered.

It has been suggested that rifaximin is less prone to resistance development compared with other rifamycins (for one of many examples, see Rivkin and Gim 2011). It is conceivable that the extremely high concentrations of rifaximin in the GI tract, nominally at least $8000 \mu \mathrm{g} /$ ml (Jiang et al. 2000), might exceed the MIC of every rifamycin-resistant mutant, neutralizing or nullifying their selective advantage. However, the isolation of clinical strains of E. coli from IBD patients treated with rifaximin for $12 \mathrm{wk}$ revealed strains having $r p o B$ mutations, an efflux pump, or both (Kothary et al. 2013). Rifamycin-resistant strains of Enterobacteriaceae isolated from TD patients were found to be mediated by mutations in $r p o B$, by efflux, and in one case by rifaximin inactivation (Hopkins et al. 2014). Finally, starting with four clinical isolates from TD patients, rifaximin-resistant strains were selected that contained $r p o B$ mutations, and that showed enhanced expression of efflux activity (Pons et al. 2012)

A dynamic demonstration that rifaximin selects for resistance with facility in vivo is shown in Figure 2 (De Leo et al. 1986). Human volunteers donated fecal samples, and analysis of the microbiome showed no detectable rifaximinresistant mutants before dosing, whereas after $5 \mathrm{~d}$ of rifaximin treatment, Enterobacteriaceae Enterococcus, Bacteroides, Clostridium, and anaerobic cocci contained from 30\% to $90 \%$ rifaximin-resistant strains. After dosing, rifaximin selection unwound, resulting in a return of the population to the original rifamycinsensitive status. A similar elasticity of the microbiome with regard to rifamycin susceptibility was observed when fecal samples were collected from UC patients following three treatment periods of $10 \mathrm{~d}$ each, interspersed by $25 \mathrm{~d}$ of washout (Brigidi et al. 2002). Rifamycin-resistant mutants became more abundant during rifaximin treatment, and diminished in frequency during washout periods.

The conservation of the rifamycin-binding site in the $\beta$ subunit of RNA polymerase from

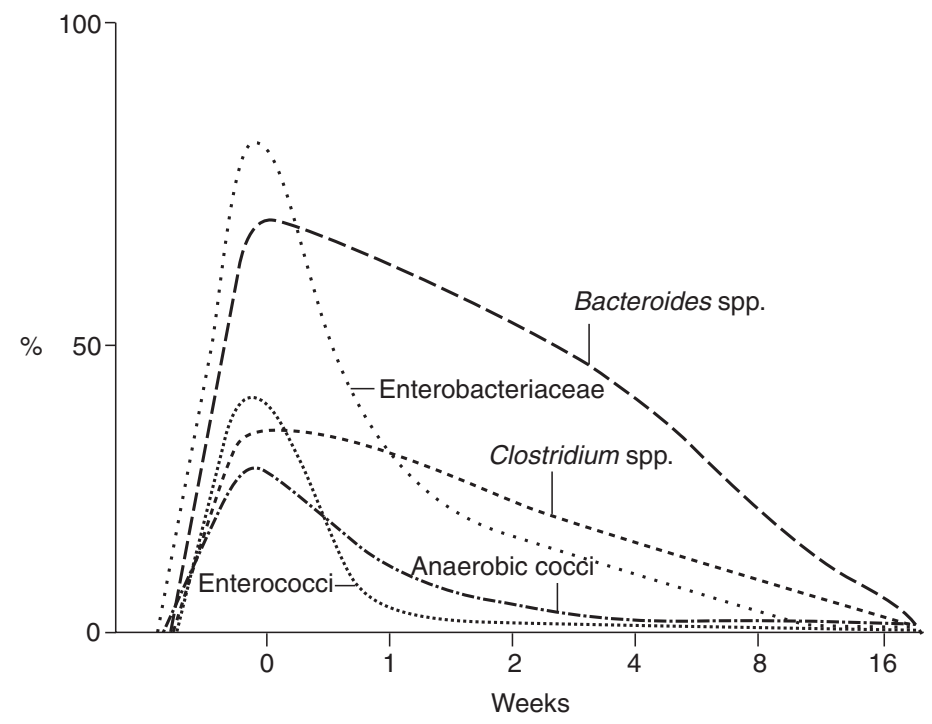

Figure 2. Percentage of bacteria resistant to rifamycins diminishes in the human gastrointestinal tract after discontinuing rifaximin treatment at week 0. (Data based on De Leo et al. 1986.) 
multiple bacterial genera suggests the importance of retaining the binding site, and a mutant that has lost the conserved site would probably be less competitively fit. Thus, once rifaximin was washed out of the GI tract, the less fit rifaximin-resistant bacteria were probably displaced by immigrant rifaximin-sensitive bacteria that were ingested. This transition to a rifaximin-sensitive microbiome may be an essential condition for future successful cycles of rifaximin treatment.

A second resistance concern, beyond the efficacy of rifaximin, is the possibility that rifaximin treatment might endanger patients by selecting for rifamycin resistance outside of the GI tract. It has already been documented that rifaximin treatment can select rifamycin-resistant strains of $S$. aureus on the skin (Valentin et al. $2011,2014)$, perhaps not so remote a danger for a patient with a prosthetic joint who was at risk for infection. The selection of resistance probably occurred because of the interface of rifaximin and $S$. aureus in the perianal area during elimination of the drug. The fact that in relatively healthy patients, the systemic exposure to rifaximin is very low mitigates the risk of selection of rifamycin resistance outside of the GI tract. However, it is important to consider that in less healthy patients, for example, cirrhotic patients, bioavailability of rifaximin can increase 10- or 20-fold (Rivkin and Gim 2011). Thus, a physician may have difficult decisions with regard to therapeutic options and risk of resistance selection outside of the GI tract, during 6 mo of rifaximin treatment with less healthy patients. Finally, the physician would hopefully be aware that branded rifaximin $\alpha$ is the crystal form that maximally confines rifaximin to the GI tract; it has the lowest systemic absorption, whereas generic rifaximin in the amorphous form may have five times the systemic exposure (Blandizzi et al. 2014).

\section{RIFAXIMIN AND C. Difficile-A BATTLE BETWEEN CURE AND RESISTANCE SELECTION}

It has been suggested that rifaximin could have utility in treating $C$. difficile infections (Rivkin and Gim 2011), as has been reported anecdotally. However, treating an invasive pathogen, $C$. difficile, with rifaximin monotherapy can lead to the failure of therapy because of the selection of a highly rifamycin-resistant $C$. difficile strain (Johnson et al. 2009). Therefore, rifaximin does not appear to be a suitable first-line monotherapeutic agent for treating C. difficile infections, in which the invading bacterium has to be eradicated. The mission is to kill the invader, not to rebalance the genome, as is the goal of rifaximin treatment for HE, IBD, or IBS. Perhaps a more appealing protocol is serial combination therapy, in which oral vancomycin would be administered for a few days, and then, when the bioburden has diminished, follow up with rifaximin to eradicate the offending organism with little chance of rifaximin-resistance development (Johnson et al. 2009). This protocol could be used in stubborn cases, in which vancomycin therapy in the past has failed.

Rifaximin-resistant $C$. difficile has been observed occasionally (O'Connor et al. 2008; Johnson et al. 2009; Carman et al. 2012). It would be wise to test the pathogen before initiating therapy, because of the instances of increases in rifamycin-resistant $C$. difficile pathogens, which have been reported to be $>30 \%$, an astonishing increase in resistance reported in specific medical centers (Curry et al. 2009; Huang et al. 2013). It is likely that rifaximin would not be successful in curing patients afflicted with a highly rifamycin-resistant strain, despite the high nominal concentration of $8000 \mu \mathrm{g} / \mathrm{ml}$ reported in fecal samples following rifaximin therapy (Jiang et al. 2000). Perhaps the best strategy is to use other options for C. difficile therapy if possible.

\section{SUMMARY}

Rifampicin continues to be very effective in combination therapies with careful selection of partner antibiotics, particularly as a mainstay therapeutic for treating active and latent TB, as well as selective, serious Gram-positive infections. Rifampicin is well established as the most essential agent to treat biofilms in PJI infections, and it is possible that its role could expand to 
D.M. Rothstein

other serious Gram-positive infections, provided that optimal combinations can be established and agreed to. One obstacle to clinical research is the lack of entrepreneurial incentive for an older drug off patent. We all benefit, however, if an infusion of money to finance clinical research is increased in the future, so that the proper evidence can lead the way to improved therapies for stubborn Gram-positive infections. Rifabutin is especially useful in treating $\mathrm{TB}$ in AIDS patients, and in preventing MAC infections. Rifabutin also has a role in H. pylori eradication as part of second-line combination therapy. Rifapentine, with its increased half-life, has potential to shorten active and latent $\mathrm{TB}$ therapy. Rifaximin, an oral drug confined to the GI tract, is used to treat GI disorders that involve dysfunction of the GI microbiome. Its efficacy for at least some indications probably has an additional (non-antibacterial) component as a regulatory effector of the pregnane $\mathrm{X}$ receptor. The continued exploration of rifaximin's uses is fostered in part by its excellent safety profile, as a drug confined to the GI tract, with both potent and broad-spectrum antibacterial activity and a soothing effect of toning down the anti-inflammatory response.

\section{ACKNOWLEDGMENTS}

I thank Andrej Trampuz (Charite-University Medicine Berlin) for his attention and advice for the section on Gram-positive systemic infections, Michael Cynamon (Syracuse Veterans Affairs Medical Center) for lending his expertise on mycobacterial infections, Simon Hirota (University of Calgary) for his interesting insights on rifamycins as effectors of the pregnane receptor, and A.L. Sonenshein (Tufts University School of Medicine) for his critical reading of the manuscript.

\section{REFERENCES}

Achermann Y, Eigenmann K, Ledergerber B, Derksen L, Rafeiner P, Clauss M, Nüesch R, Zellweger C, Vogt M, Zimmerli W. 2013. Factors associated with rifampin resistance in staphylococcal periprosthetic joint infections (PJI): A matched case-control study. Infection 41: 431437.
Adachi JA, DuPont HL. 2006. Rifaximin: A novel nonabsorbed rifamycin for gastrointestinal disorders. Clin Infect Dis 42: 541-547.

Amorena B, Gracia E, Monzón M, Leiva J, Oteiza C, Pérez M, Alabart JL, Hernández-Yago J. 1999. Antibiotic susceptibility assay for Staphylococcus aureus in biofilms developed in vitro. J Antimicrob Chemother 44: 43-55.

Aubry-Damon H, Soussy CJ, Courvalin P. 1998. Characterization of mutations in the rpoB gene that confer rifampin resistance in Staphylococcus aureus. Antimicrob Agents Chemother 42: 2590-2594.

Baldoni D, Haschke M, Rajacic Z, Zimmerli W, Trampuz A. 2009. Linezolid alone or combined with rifampin against methicillin-resistant Staphylococcus aureus in experimental foreign-body infection. Antimicrob Agents Chemother 53: $1142-1148$.

Bass NM, Mullen KD, Sanyal A, Poordad F, Neff G, Leevy CB, Sigal S, Sheikh MY, Beavers K, Frederick T, et al. 2010. Rifaximin treatment in hepatic encephalopathy. $N$ Engl J Med. 362: 1071-1081.

Billington OJ, McHugh TD, Gillespie SH. 1999. Physiological cost of rifampin resistance induced in vitro in $\mathrm{Myco-}$ bacterium tuberculosis. Antimicrob Agents Chemother 43: $1866-1869$.

Blandizzi C, Viscomi GC, Scarpignato C. 2014. Impact of crystal polymorphism on the systemic bioavailability of rifaximin, an antibiotic acting locally in the gastrointestinal tract, in healthy volunteers. Drug Des Devel Ther 9: $1-11$

Boeree MJ, Diacon AH, Dawson R, Narunsky K, du Bois J, Venter A, Phillips PP, Gillespie SH, McHugh TD, Hoelscher M, et al. 2015. A dose-ranging trial to optimize the dose of rifampin in the treatment of tuberculosis. Am J Respir Crit Care Med 191: 1058-1065.

Brigidi P, Swennen E, Rizzello F, Bozzolasco M, Matteuzzi D. 2002. Effects of rifaximin administration on the intestina microbiota in patients with ulcerative colitis. J Chemother 14: $290-295$.

Burman WJ, Gallicano K, Peloquin C. 2001. Comparative pharmacokinetics and pharmacodynamics of the rifamycin antibacterials. Clin Pharmacokinet 40: 327-341.

Burman W, Benator D, Vernon A, Khan A, Jones B, Silva C, Lahart C, Weis S, King B, Mangura B, et al. 2006. Acquired rifamycin resistance with twice-weekly treatment of HIV-related tuberculosis. Am J Respir Crit Care Med 173: $350-356$.

Carman RJ, Boone JH, Grover H, Wickham KN, Chen L. 2012. In vivo selection of rifamycin-resistant Clostridium difficile during rifaximin therapy. Antimicrob Agents Chemother 56: 6019-6020.

Chen LF, Kaye D. 2009. Current use for old antibacterial agents: Polymyxins, rifamycins, and aminoglycosides. Infect Dis Clin North Am 7523: 1053-1075.

Cheng J, Shah YM, Ma X, Pang X, Tanaka T, Kodama T, Krausz KW, Gonzalez FJ. 2010. Therapeutic role of rifaximin in inflammatory bowel disease: Clinical implication of human pregnane X receptor activation.J Pharmacol Exp Ther 335: 32-41.

Cho JH, Brant SR. 2011. Recent insights into the genetics of inflammatory bowel disease. Gastroenterology 140: 1704-1712. 
Costerton JW, Stewart PS, Greenberg EP. 1999. Bacterial biofilms: A common cause of persistent infections. Science 284: 1318-1322.

Curry SR, Marsh JW, Shutt KA, Muto CA, O’Leary MM, Saul MI, Pasculle AW, Harrison LH. 2009. High frequency of rifampin resistance identified in an epidemic Clostridium difficile clone from a large teaching hospital. Clin Infect Dis 48: 425-429.

Darkoh C, Lichtenberger LM, Ajami N, Dial EJ, Jiang ZD, DuPont HL. 2010. Bile acids improve the antimicrobial effect of rifaximin. Antimicrob Agents Chemother 54: $3618-3624$.

De Leo C, Eftimiadi C, Schito GC. 1986. Rapid disappearance from the intestinal tract of bacteria resistant to rifaximin. Drugs Exp Clin Res 12: 979- 981.

Dring MM, Goulding CA, Trimble VI, Keegan D, Ryan AW, Brophy KM, Smyth CM, Keeling PW, O’Donoghue D, O'Sullivan M, et al. 2006. The pregnane $\mathrm{X}$ receptor locus is associated with susceptibility to inflammatory bowel disease. Gastroenterology 130: 341-348.

Dworkin RJ, Lee BL, Sande MA, Chambers HF. 1989. Treatment of right-sided Staphylococcus aureus endocarditis in intravenous drug users with ciprofloxacin and rifampicin. Lancet 334: 1071-1073.

Field SK, Fisher D, Jarand JM, Cowie RL. 2012. New treatment options for multidrug-resistant tuberculosis. Ther Adv Respir Dis 6: 255-268.

Forrest GN, Tamura K. 2010. Rifampin combination therapy for nonmycobacterial infections. Clin Microbiol Rev 23: $14-34$.

Fox W, Ellard GA, Mitchison DA. 1999. Studies on the treatment of tuberculosis undertaken by the British Medical Research Council tuberculosis units, 1946-1986, with relevant subsequent publications. Int J Tuberc Lung Dis 3: S231-S279.

Furustrand Tafin U, Corvec S, Betrisey B, Zimmerli W, Trampuz A. 2012. Role of rifampin against Propionibacterium acnes biofilm in vitro and in an experimental foreign-body infection model. Antimicrob Agents Chemother 56: $1885-1891$.

Getahun H, Matteelli A, Chaisson RE, Raviglione M. 2015. Latent Mycobacterium tuberculosis infection. N Engl J Med 372: 2127-2135.

Gisbert JP, Calvet X. 2012. Review article: Rifabutin in the treatment of refractory Helicobacter pylori infection. Aliment Pharmacol Ther 35: 209-221.

Goldstein BP. 2014. Resistance to rifampicin: A review. J Antibiot 67: 625-630.

Gomes F, Teixeira P, Ceri H, Oliveira R. 2012. Evaluation of antimicrobial activity of certain combinations of antibiotics against in vitro Staphylococcus epidermidis biofilms. Indian J Med Res 135: 542-547.

Guslandi M. 2011. Rifaximin in the treatment of inflammatory bowel disease. World J Gastroenterol 17: 4643-4646.

Habib G, Lancellotti P, Antunes MJ, Bongiorni MG, Casalta JP, Del Zotti F, Dulgheru R, El Khoury G, Erba PA, Iung B, et al. 2015. 2015 ESC Guidelines for the management of infective endocarditis: The Task Force for the Management of Infective Endocarditis of the European Society of Cardiology (ESC) Endorsed by: European Association for Cardio-Thoracic Surgery (EACTS), the European As- sociation of Nuclear Medicine (EANM). Eur Heart J 36: 3075-3128.

Heldman AW, Hartert TV, Ray SC, Daoud EG, Kowalski TE, Pompili VJ, Sisson SD, Tidmore WC, vom Eigen KA, Goodman SN, et al. 1996. Oral antibiotic treatment of right-sided staphylococcal endocarditis in injection drug users: Prospective randomized comparison with parenteral therapy. Am J Med 101: 68-76.

Hirota SA. 2015. Understanding the molecular mechanisms of rifaximin in the treatment of gastrointestinal disorders-A focus on the modulation of host tissue function. Mini Rev Med Chem 16: 206-217.

Hoover WW, Gerlach EH, Hoban DJ, Eliopoulos GM, Pfaller MA, Jones RN. 1993. Antimicrobial activity and spectrum of rifaximin, a new topical rifamycin derivative. Diagn Microbiol Infect Dis 16: 111-118.

Hopkins KL, Mushtaq S, Richardson JF, Doumith M, de Pinna E, Cheasty T, Wain J, Livermore DM, Woodford N. 2014. In vitro activity of rifaximin against clinical isolates of Escherichia coli and other enteropathogenic bacteria isolated from travellers returning to the UK. Int J Antimicrob Agents 43: 431-437.

Horsburgh CR, Rubin EJ. 2011. Clinical practice. Latent tuberculosis infection in the United States. $N$ Engl J Med 364: 1441-1448.

Hu Y, Ren J, Zhan M, Li W, Dai H. 2012. Efficacy of rifaximin in prevention of travelers' diarrhea: A meta-analysis of randomized, double-blind, placebo-controlled trials. $J$ Travel Med 19: 352-356.

Huang JS, Jiang ZD, Garey KW, Lasco T, Dupont HL. 2013. Use of rifamycin drugs and development of infection by rifamycin-resistant strains of Clostridium difficile. Antimicrob Agents Chemother 57: 2690-2693.

Iorio N, Malik Z, Schey R. 2015. Profile of rifaximin and its potential in the treatment of irritable bowel syndrome. Clin Exp Gastroenterol 8: 159-167.

Jacqueline C, Caillon J. 2014. Impact of bacterial biofilm on the treatment of prosthetic joint infections. J Antimicrob Chemother 69: 37-40.

Jiang ZD, Ke S, Palazzini E, Riopel L, Dupont H. 2000. In vitro activity and fecal concentration of rifaximin after oral administration. Antimicrob Agents Chemother 44: 2205-2206.

Jiang ZD, DuPont HL, La Rocco M, Garey KW. 2010. In vitro susceptibility of Clostridium difficile to rifaximin and rifampin in 359 consecutive isolates at a university hospital in Houston, Texas. J Clin Pathol 63: 355-358.

Jindani A, Doré CJ, Mitchison DA. 2003. Bactericidal and sterilizing activities of antituberculosis drugs during the first 14 days. Am J Respir Crit Care Med 167: 1348-1354.

Jindani A, Harrison TS, Nunn AJ, Phillips PP, Churchyard GJ, Charalambous S, Hatherill M, Geldenhuys H, McIlleron HM, Zvada SP, et al. 2014. High-dose rifapentine with moxifloxacin for pulmonary tuberculosis. $N \mathrm{Engl} \mathrm{J}$ Med 371: 1599-1608.

John AK, Baldoni D, Haschke M, Rentsch K, Schaerli P, Zimmerli W, Trampuz A. 2009. Efficacy of daptomycin in implant-associated infection due to methicillin-resistant Staphylococcus aureus: Importance of combination with rifampin. Antimicrob Agents Chemother 53: 2719 2724. 
D.M. Rothstein

Johnson S, Schriever C, Patel U, Patel T, Hecht DW, Gerding DN. 2009. Rifaximin redux: Treatment of recurrent Clostridium difficile infections with rifaximin immediately post-vancomycin treatment. Anaerobe 15: 290-291.

Kassinen A, Krogius-Kurikka L, Mäkivuokko H, Rinttilä T, Paulin L, Corander J, Malinen E, Apajalahti J, Palva A. 2007. The fecal microbiota of irritable bowel syndrome patients differs significantly from that of healthy subjects. Gastroenterology 133: 24-33.

Klemens SP, Grossi MA, Cynamon MH. 1994. Comparative in vivo activities of rifabutin and rifapentine against $M y$ cobacterium avium complex. Antimicrob Agents Chemother 38: 234-237.

Kothary V, Scherl EJ, Bosworth B, Jiang ZD, Dupont HL, Harel J, Simpson KW, Dogan B. 2013. Rifaximin resistance in Escherichia coli associated with inflammatory bowel disease correlates with prior rifaximin use, mutations in $r p o B$, and activity of Phe-Arg- $\beta$-naphthylamideinhibitable efflux pumps. Antimicrob Agents Chemother 57: $811-817$.

Kunin CM. 1996. Antimicrobial activity of rifabutin. Clin Infect Dis 22: S3-S14.

Langmann T, Moehle C, Mauerer R, Scharl M, Liebisch G, Zahn A, Stremmel W, Schmitz G. 2004. Loss of detoxification in inflammatory bowel disease: Dysregulation of pregnane X receptor target genes. Gastroenterology 127: $26-40$.

Levine DP, Fromm BS, Reddy BR. 1991. Slow response to vancomycin or vancomycin plus rifampin in methicillinresistant Staphylococcus aureus endocarditis. Ann Intern Med 115: 674-680.

Ma X, Shah YM, Guo GL, Wang T, Krausz KW, Idle JR, Gonzalez FJ. 2007. Rifaximin is a gut-specific human pregnane X receptor activator. J Pharmacol Exp Ther 322: 391-398.

Mariam DH, Mengistu Y, Hoffner SE, Andersson DI. 2004 Effect of $r p o B$ mutations conferring rifampin resistance on fitness of Mycobacterium tuberculosis. Antimicrob Agents Chemother 48: 1289-1294.

Mihailescu R, Furustrand Tafin U, Corvec S, Oliva A, Betrisey B, Borens O, Trampuz A. 2014. High activity of fosfomycin and rifampin against methicillin-resistant Staphylococcus aureus biofilm in vitro and in an experimental foreign-body infection model. Antimicrob Agents Chemother 58: 2547-2553.

Mitchison D, Davies G. 2012. The chemotherapy of tuberculosis: Past, present and future. Tuberc Lung Dis 16: $724-732$.

Mitnick CD, McGee B, Peloquin CA. 2009. Tuberculosis pharmacotherapy: Strategies to optimize patient care. Expert Opin Pharmacother 10: 381-401.

Mullen KD, Sanyal AJ, Bass NM, Poordad FF, Sheikh MY, Frederick RT, Bortey E, Forbes WP. 2014. Rifaximin is safe and well tolerated for long-term maintenance of remission from overt hepatic encephalopathy. Clin Gastroenterol Hepatol 12: 1390-1397.

Munsiff SS, Kambili C, Ahuja SD. 2006. Rifapentine for the treatment of pulmonary tuberculosis. Clin Infect Dis $\mathbf{4 3}$ $1468-1475$.

Murphy CK, Mullin S, Osburne MS, van Duzer J, Siedlecki J, Yu X, Kerstein K, Cynamon M, Rothstein DM. 2006. In vitro activity of novel rifamycins against rifamycin-resis- tant Staphylococcus aureus. Antimicrob Agents Chemother 50: $827-834$.

Neu HC. 1983. Antibacterial activity of DL 473, a C3-substituted rifamycin derivative. Antimicrob Agents Chemother 24: 457-460.

Nuermberger EL, Spigelman MK, Yew WW. 2010. Current development and future prospects in chemotherapy of tuberculosis. Respirology 15: 764-778.

O’Brien RJ, Vernon AA. 1998. New tuberculosis drug development. How can we do better? Am J Respir Crit Care Med 157: 1705-1707.

O'Connor JR, Galang MA, Sambol SP, Hecht DW, Vedantam G, Gerding DN, Johnson S. 2008. Rifampin and rifaximin resistance in clinical isolates of Clostridium difficile. Antimicrob Agents Chemother 52: 2813-2817.

O'Neill AJ, Huovinen T, Fishwick CW, Chopra I. 2006. Molecular genetic and structural modeling studies of Staphylococcus aureus RNA polymerase and the fitness of rifampin resistance genotypes in relation to clinical prevalence. Antimicrob Agents Chemother 50: 298-309.

Osmon DR, Berbari EF, Berendt AR, Lew D, Zimmerli W, Steckelberg JM, Rao N, Hanssen A, Wilson WR; Infectious Diseases Society of America. 2013. Diagnosis and management of prosthetic joint infection: Clinical practice guidelines by the Infectious Diseases Society of America. Clin Infect Dis 56: e1-e25.

Patidar KR, Bajaj JS. 2013. Antibiotics for the treatment of hepatic encephalopathy. Metab Brain Dis 28: 307-312.

Peel TN, Buising KL, Dowsey MM, Aboltins CA, Daffy JR, Stanley PA, Choong PF. 2013. Outcome of debridement and retention in prosthetic joint infections by methicillin-resistant Staphylococci, with special reference to rifampin and fusidic acid combination therapy. Antimicrob Agents Chemother 57: 350-355.

Perlroth J1, Kuo M, Tan J, Bayer AS, Miller LG. 2008. Adjunctive use of rifampin for the treatment of Staphylococcus aureus infections: A systematic review of the literature. Arch Intern Med 168: 805-819.

Pimentel M, Lembo A, Chey WD, Zakko S, Ringel Y, Yu J, Mareya SM, Shaw AL, Bortey E, Forbes WP; TARGET Study Group. 2011a. Rifaximin therapy for patients with irritable bowel syndrome without constipation. $N$ Engl J Med 364: 22-32.

Pimentel M, Morales W, Chua K, Barlow G, Weitsman S, Kim G, Amichai MM, Pokkunuri V, Rook E, Mathur R, et al. 2011b. Effects of rifaximin treatment and retreatment in nonconstipated IBS subjects. Dig Dis Sci 56: 20672072.

Pistiki A, Galani I, Pyleris E, Barbatzas C, Pimentel M, Giamarellos-Bourboulis EJ. 2014. In vitro activity of rifaximin against isolates from patients with small intestinal bacterial overgrowth. Int J Antimicrob Agents 43: $236-$ 241.

Pons MJ, Mensa L, Gascón J, Ruiz J. 2012. Fitness and molecular mechanisms of resistance to rifaximin in in vitro selected Escherichia coli mutants. Microb Drug Resist 18: 376-379.

Prantera C, Lochs H, Campieri M, Scribano ML, Sturniolo GC, Castiglione F, Cottone M. 2006. Antibiotic treatment of Crohn's disease: Results of a multicentre, double blind, randomized, placebo-controlled trial with rifaximin. $\mathrm{Al}$ iment Pharmacol Ther 23: 1117-1125. 
Prantera C, Lochs H, Grimaldi M, Danese S, Scribano ML Gionchetti P; Retic Study Group (Rifaximin-EIR Treatment in Crohn's Disease). 2012. Rifaximin-extended intestinal release induces remission in patients with moderately active Crohn's disease. Gastroenterology 142: 473 481.

Rastogi N, Goh KS, Berchel M, Bryskier A. 2000. Activity of rifapentine and its metabolite 25-O-desacetylrifapentine compared with rifampicin and rifabutin against $\mathrm{Myco-}$ bacterium tuberculosis, Mycobacterium africanum, $\mathrm{Myco-}$ bacterium bovis and M. bovis BCG. J Antimicrob Chemother 46: 565-570.

Regazzi M, Carvalho AC, Villani P, Matteelli A. 2014. Treatment optimization in patients co-infected with HIV and Mycobacterium tuberculosis infections: Focus on drugdrug interactions with rifamycins. Clin Pharmacokinet 53: 489-507.

Rivkin A, Gim S. 2011. Rifaximin: New therapeutic indication and future directions. Clin Ther 33: 812-827.

Saadi M, McCallum RW. 2013. Rifaximin in irritable bowel syndrome: Rationale, evidence and clinical use. Ther $A d v$ Chronic Dis 4: 71-75.

Saginur R, Stdenis M, Ferris W, Aaron SD, Chan F, Lee C, Ramotar K. 2006. Multiple combination bactericidal testing of staphylococcal biofilms from implant-associated infections. Antimicrob Agents Chemother 50: 55-61.

Saleh-Mghir A, Muller-Serieys C, Dinh A, Massias L, Crémieux AC. 2011. Adjunctive rifampin is crucial to optimizing daptomycin efficacy against rabbit prosthetic joint infection due to methicillin-resistant Staphylococcus aureus. Antimicrob Agents Chemother 55: 4589-4893.

Sanders WE. 1976. Rifampin. Ann Intern Med 85: 82-86.

Schrenzel J, Harbarth S, Schockmel G, Genné D, Bregenzer T, Flueckiger U, Petignat C, Jacobs F, Francioli P, Zimmerli W, et al. 2004. A randomized clinical trial to compare fleroxacin-rifampicin with flucloxacillin or vancomycin for the treatment of staphylococcal infection. Clin Infect Dis 39: 1285-1292.

Scott LJ. 2014. Rifaximin: A review of its use in reducing recurrence of overt hepatic encephalopathy episodes. Drugs 74: 2153-2160.

Silver LL. 2011. Challenges of antibacterial discovery. Clin Microbiol Rev 24: 71-109.

Stagg HR, Zenner D, Harris RJ, Muñoz L, Lipman MC, Abubakar I. 2014. Treatment of latent tuberculosis infection: A network meta-analysis. Ann Intern Med 161: 419-428.

Sussman NL. 2015. Treatment of overt hepatic encephalopathy. Clin Liver Dis 19: 551-563.

Taylor DN, Bourgeois AL, Ericsson CD, Steffen R, Jiang ZD, Halpern J, Haake R, Dupont HL. 2006. A randomized, double-blind, multicenter study of rifaximin compared with placebo and with ciprofloxacin in the treatment of travelers' diarrhea. Am J Trop Med Hyg 74: 1060-1066.

Thornsberry C, Hill BC, Swenson JM, McDougal LK. 1983. Rifampin: Spectrum of antibacterial activity. Rev Infect Dis 3: S412-S417.

Tupin A, Gualtieri M, Roquet-Banères F, Morichaud Z, Brodolin K, Leonetti JP. 2010. Resistance to rifampicin: At the crossroads between ecological, genomic and medical concerns. Int J Antimicrob Agents 35: 519-523.
Valentin T, Leitner E, Rohn A, Zollner-Schwetz I, Hoenigl M, Salzer HJ, Krause R. 2011. Rifaximin intake leads to emergence of rifampin-resistant Staphylococci. J Infect 62: $34-38$.

Valentin T, Hoenigl M, Wagner J, Krause R, Zollner-Schwetz I. 2014. Bacteraemia with rifampin-resistant Staphylococcus aureus and the potential role of cross-resistance between rifampin and rifaximin. J Infect 69: 295-297.

Van der Auwera P, Klastersky J, Thys JP, Meunier-Carpentier F, Legrand JC. 1985. Double-blind, placebo-controlled study of oxacillin combined with rifampin in the treatment of staphylococcal infections. Antimicrob Agents Chemother 28: 467-472.

Vergidis P, Rouse MS, Euba G, Karau MJ, Schmidt SM, Mandrekar JN, Steckelberg JM, Patel R. 2011. Treatment with linezolid or vancomycin in combination with rifampin is effective in an animal model of methicillin-resistant Staphylococcus aureus foreign body osteomyelitis. Antimicrob Agents Chemother 55: 1182-1186.

Wichelhaus TA, Schäfer V, Brade V, Böddinghaus B. 1999. Molecular characterization of rpoB mutations conferring cross-resistance to rifamycins on methicillin-resistant Staphylococcus aureus. Antimicrob Agents Chemother 43: 2813-2816.

Wichelhaus TA, Böddinghaus B, Besier S, Schäfer V, Brade V, Ludwig A. 2002. Biological cost of rifampin resistance from the perspective of Staphylococcus aureus. Antimicrob Agents Chemother 46: 3381-3385.

Widmer AF, Frei R, Rajacic Z, Zimmerli W. 1990. Correlation between in vivo and in vitro efficacy of antimicrobial agents against foreign body infections. Correlation between in vivo and in vitro efficacy of antimicrobial agents against foreign body infections. J Infect Dis 162: 96-102.

Widmer AF, Gaechter A, Ochsner PE, Zimmerli W. 1992. Antimicrobial treatment of orthopedic implant-related infections with rifampin combinations. Clin Infect Dis 14: $1251-1253$.

Williams DL, Spring L, Gillis TP, Salfinger M, Persing DH 1998. Evaluation of a polymerase chain reaction-based universal heteroduplex generator assay for direct detection of rifampin susceptibility of Mycobacterium tuberculosis from sputum specimens. Clin Infect Dis 26: 446450.

Zhang J, Zhu L, Stonier M, Coumbis J, Xu X, Wu Y, Arikan D, Farajallah A, Bertz R. 2011. Determination of rifabutin dosing regimen when administered in combination with ritonavir-boosted atazanavir. J Antimicrob Chemother 66: 2075-2082.

Zimmerli W, Waldvogel FA, Vaudaux P, Nydegger UE. 1982. Pathogenesis of foreign body infection: Description and characteristics of an animal model. J Infect Dis 146: 487497.

Zimmerli W, Widmer AF, Blatter M, Frei R, Ochsner PE. 1998. Role of rifampin for treatment of orthopedic implant-related staphylococcal infections: A randomized controlled trial. Foreign-Body Infection (FBI) Study Group. JAMA 279: 1537-1541.

Zimmerli W, Trampuz A, Ochsner PE. 2004. Prostheticjoint infections. N Engl J Med 351: 1645-1654. 


\section{$\&_{\mathrm{CSH}}^{\infty} \&$ Cold Spring Harbor

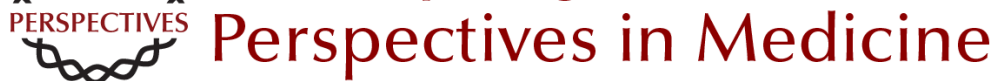

\section{Rifamycins, Alone and in Combination}

David M. Rothstein

Cold Spring Harb Perspect Med 2016; doi: 10.1101/cshperspect.a027011 originally published online June 7, 2016

\section{Subject Collection Antibiotics and Antibiotic Resistance}

Fosfomycin: Mechanism and Resistance Lynn L. Silver

Pleuromutilins: Potent Drugs for Resistant Bugs

--Mode of Action and Resistance Susanne Paukner and Rosemarie Riedl

Appropriate Targets for Antibacterial Drugs Lynn L. Silver

Lincosamides, Streptogramins, Phenicols, and Pleuromutilins: Mode of Action and Mechanisms of Resistance

Stefan Schwarz, Jianzhong Shen, Kristina Kadlec, et al.

Resistance to Macrolide Antibiotics in Public Health Pathogens

Corey Fyfe, Trudy H. Grossman, Kathy Kerstein, et al.

Bacterial Protein Synthesis as a Target for

Antibiotic Inhibition

Stefan Arenz and Daniel N. Wilson

Antibacterial Antifolates: From Development through Resistance to the Next Generation Alexavier Estrada, Dennis L. Wright and Amy C. Anderson

Antibacterial Drug Discovery Targeting the Lipopolysaccharide Biosynthetic Enzyme LpxC Alice L. Erwin
The Whys and Wherefores of Antibiotic

Resistance

Cameron R. Strachan and Julian Davies

$\beta$-Lactamases: A Focus on Current Challenges Robert A. Bonomo

Approved Glycopeptide Antibacterial Drugs: Mechanism of Action and Resistance Daina Zeng, Dmitri Debabov, Theresa L. Hartsell, et al.

Mechanism of Action and Resistance to Daptomycin in Staphylococcus aureus and Enterococci William R. Miller, Arnold S. Bayer and Cesar A. Arias

Polymyxin: Alternative Mechanisms of Action and Resistance

Michael J. Trimble, Patrik Mlynárcik, Milan Kolár, et al.

Topoisomerase Inhibitors: Fluoroquinolone

Mechanisms of Action and Resistance David C. Hooper and George A. Jacoby

$\beta$-Lactams and $\beta$-Lactamase Inhibitors: An Overview Karen Bush and Patricia A. Bradford

Rifamycins, Alone and in Combination David M. Rothstein

For additional articles in this collection, see http://perspectivesinmedicine.cshlp.org/cgi/collection/ 